\title{
V. Narrative of an excursion to the summit of the peak of Teneriffe on the 23rd and 24th of February 1829
}

\section{Robert Edward Alison Esq.}

To cite this article: Robert Edward Alison Esq. (1830) V. Narrative of an excursion to the summit of the peak of Teneriffe on the 23rd and 24th of February 1829, Philosophical Magazine Series 2, 8:43, 23-30, DOI: 10.1080/14786443008675354

To link to this article: http://dx.doi.org/10.1080/14786443008675354

电 Published online: 13 Jul 2009.

Submit your article to this journal $\pi$

Џll Article views: 2

Q View related articles $\sqsubset$ 
speed was not particularly entered, it could not be less than at the rate of $2 \frac{1}{2}$ miles per hour.

As these experiments were fairly made, and by horses of the common breed used by farmers, and upon ploughs from various counties, these numbers may be considered as a pretty accurate measure of the force actually exerted by horses at plough, and which they are able to do without injury for many weeks;-but it should be remembered, that if these horses had been put out of their usual walking pace, the result would have been very different. The mean power of the draught-horse, deduced from the above-mentioned experiments, exceeds the calculated power from the highest formula of Mr. Leslie. I am, Gentlemen,

Your obedient servant,

B. Bevan.

V. Narrative of an Excursion to the Summit of the Peak of Teneriffe on the 23rd and 24th of Felruary 1829. By Rober'T Edward Alison, Esq.*

H AVING frequently observed the rapid fall of the atmospheric temperature when ascending from the sea-coast of Teneriffe to an elevation of 1000 feet, and on the contrary. the very slow alteration at higher points, I was desirous of ascertaining the proportional decrement of heat in the upper regions.

The ascent to the top of the Peak of Teneriffe is considered by the natives of the island as impracticable in the winter season, on account of the snow and the supposed extreme cold; it is therefore seldom made before the month of June, when it is free from snow: but I was not able to wait for a more genial season, as I was in daily expectation of returning to England; I therefore resolved to make the attempt.

On the 23rd of February, at 4 A.M., I left the Augustine convent Orotuca, which is situated nearly 1100 feet above the level of the sea. At the time of my departure the thermometer stood at $56^{\circ} \cdot 5$, and there was a gentle breeze from the N.N.W.

After joining a stout active young peasant who was to act as my guide, we entered the "Camino de C'rasna," which is dignified by the name of a road, although, like almost all the highways in the island, it is only a steep and uneven line of

- Communicated by the Author. 
lava. An ascent of 500 feet took us to the extremity of the beautiful zone of vines, and at half-past six A.M. we crossed the barranco or ravine Penilla; the surface here gradually began to assume a different appearance, from the vegetation which clothed it being common to Europe.

Shortly after leaving the zone of chestnuts and lupines, we entered a belt of heaths which form the third region of plants; this belt is about four miles long, and a quarter of a mile broad, and extends nearly across the valley of Orotava. The temperature here began to decrease very sensibly; and although the lavas in some places were only covered with a few inches of decomposed volcanic and vegetable matter, yet they were clothed with a most luxuriant verdure. This is no doubt to be attributed to the moisture from the clouds, which frequently completely envelop even this inferior elevation towards the close of the day, or before or after any sudden alteration of temperature.

Fifteen minutes after leaving the last barranco, we crossed another, called Pilloni, which is rather more than 3000 feet above the sea; and soon after, we entered the Barranco del Pino Dornajito, which is 3410 feet above the sea*; it is so named from an enormous pine-tree that grew near the western side of the ravine. It is said that this tree was full-grown at the time of the conquest of the island, 360 years ago ;-thus, having stood the storms of so many ages, it was at last swept into the ravine by the dreadful waterspout that devastated the island on the 7th of November 1826. Although this tree is partly destroyed by its fall, yet it still measures 128 feet in length, and 30 in circumference.

Under a precipice in the middle of the ravine is a small spring of water, with a wooden cross at the side of it; the temperature of the spring was $56^{\circ}$, but it appears to vary more than any other which I have examined, as in October the temperature of the water was $65^{\circ} \cdot 5$. At the time of the before-mentioned waterspout, a body of water, some hundred feet wide and thirty or forty deep, fell over this spring and cross without doing it the least damage; which the peasantry attribute to the Divine interposition, forgetting that the water, in falling from the height above, would form a curve and effectually protect it from injury.

From the great depth of this ravine, the various strata of lava can be observed; the superior stratum consists of decom-

- According to a barometrical admeasurement made by Humboldt and calculated by the formula of Laplace.

posed 
posed lava and regetable mould, to the depth of three feet; next is a sort of yolcanic breccia or conglomerate, held together by a brown mud and tufa; afterwards a bed of volcanic tufa, of four or five feet in thickness, succeeded by alternate strata of compact bluish-coloured basaltic trap and brown mud. In the bed of the ravine were large blocks of lava mixed with hornblende and augite.

In my first ascent to the Peak I was much disappointed in not meeting with the forest of pine-trees above the zone of chestnuts, which the visitors to the Peak during the last century mention with so much pleasure; but the destructive axe has not left a single trace of them. On the way towards the defile of the Portillo, there are several spots pointed out as famous for the enormous size of a particular pine-tree, such as Pino del Dornajito, Pino de la Caravela, Pino de la Merienda, and Ultimo Pino.

A short distance above Dornajito the surface is intersected by numerous small ravines, and the soil is so thin that the lava frequently appears above the surface. Ascending a little further we approached the lower region of the clouds, where we found the temperature begin to fall rather rapidly; but at the same time vegetation became so luxuriant, that it was difficult to observe the nature of the lavas. The tree heatbs (Erica arborea) are of considerable size, being sometimes sixteen or eighteen feet high, with stems half the thickness of a man's body ; they are mixed with the laurel, cytisus, and various other arborescent shrubs : it is worthy of remark, that all the leaves of the different shrubs here are of the same size, form and colour, which is a brilliant dark green. This strong vegetation is certainly produced by the hamidity of the atmosphere, from the clouds generally resting at this elevation during the night and early part of the morning.

What makes this more evident is, that -as you advance to the verge of this climate, where the air is drier and the sun's rays more powerful, vegetation becomes less luxuriant, and the leaves are of a light green instead of a dark green colour.

The lavas here appeared to have flowed in numerous streams from various openings; they look like a sort of wacken: their colour is black, rather vesicular, and they contain greencoloured augite, hornblende, and olivine, and all affect the magnetic needle strongly. Many of the lavas are much decomposed, with the pores on the outside free from crystals, which have no doubt fallen out, as I always found them internally.

N.S. Vol. 8. No. 43. July 1830.

E

We 
We still gradually ascended; and as we crossed Barranco Haya we were rather annoyed by the lower region of clouds condensing on our clothes and bodies, and producing by the evaporation a degree of cold considerably greater than that indicated by the thermometer, which was $49 \cdot 5$; we likewise encountered a strong current of air blowing from the west-by-south, although both above and below us the wind was blowing from the N.N.W. This current of air was produced probably by the wind sweeping down the western extremity of the mountain called Tigayga, into the entrance of the Cañadas, between the Cavison and the Portillo (which is a sort of defile or opening in the chain of mountains that surround the Cañadas), thus creating a considerable pressure of air, which caused a rush of wind into the valley below.

Some distance above Barranco Haya we crossed an ancient stream of lava, which appeared to have proceeded from a volcano to the S.S.W., but it was so covered with vegetation that it was difficult to discover its composition. The detached pieces which I picked up were a porphyritic trachyte, with crystals of augite and felspar, partly destroyed by fire.

At $\frac{1}{4}$ to 8 A.M. we crossed the ravine named Fuera el Monte, and entered the Llanos de Gaspar (the plains of Gaspar). Here vegetation became very scanty, and almost the only plant was Canarian thyme. But this spot is particularly interesting, from its being evident that a considerable part of the waterspout which deluged the island in November 1826 had burst here, cutting the surface into a vast number of ravines, some of them of great depth. From the appearance of the surface, the columns of water which fell must have been very numerous; as in ten or twelve different places the lava is cut into deep trenches, some of them fifteen and twenty feet deep, with the soil which was between them completely washed away by the spray or overflowing of the water. Many of these deep channels frequently converge into one, forming a destructive and overwhelming ravine.

Considerable bodies of water have frequently fallen upon the Canaries, and done some mischief by washing into the sea the vegetable mould which so thinly covers the lavas. But the visitation of the 6th and 7 th of November 1826 was the most awful and destructive, both to life and property, of any of which the inhabitants have any tradition. My friend $\mathrm{Mr}$. Auber; of Orotava, has furnished me with the interesting details of the phænomena attending this waterspout, which I shall here subjoin.

On the afternoon of the 6 th of November, the wind, which 
was blowing strongly from the N.E., veered round to every point of the compass, and ultimately established itself from the north; but at sea, a few miles from land, it was blowing a hurricane from the N.E., and in a moment, without any intermediate change, it blew as strongly from the S.W. The sky became obscured all at once by enormous masses of black clouds, which hastened the night some time before sunset; but neither thunder nor lightning was observed. The rain commenced to fall in torrents towards 10 o'clock at night, and the wind to blow with an overpowering impetuosity. $\mathbf{A t}$ half-past two on the morning of the 7th, Mr. Auber observed several globes of fire moving upon the sea, at various distances from the shore, whilst others remained stationary. One of them, from its position, appeared to be on the top of the Montañeta of Realejo, and caused him to suppose that that extinct volcano was going to threaten the valley of Orotava with an eruption: but he was soon undeceived, by observing that the globe moved about on the surface of the water like the others, and at some distance from the spot where he first thought it was situated.

These luminous globes appeared to move towards the S.W. and follow the direction of the waves. The light which they spread in the atmosphere extended more than $45^{\circ}$ high; and although he was three miles off, it was often sufficiently strong to enable him to read rather small print; but no detonation was heard. The number of globes increased from half-past two o'clock till four, when they began to diminish. Mr. Auber, at one period of his observations, counted fourteen moving about at one time; but the glare of light which he perceived on his right, where the surrounding houses bounded his view, caused him to suppose their number to be much more considerable. Their duration was from one minute to five or six, but seldom longer; and their apparent diameter was about the half of that of the moon at her full, when she reaches the zenith. When they had all disappeared the darkness was extreme, and he could not see the neighbouring houses; but a quarter of an hour afterwards, the reappearance of the same globes, or the formation of new ones, allowed him to see the island of Palma, though nearly sixty miles distant. The rain fell with equal force whilst these globes were appearing upon the sea and after their disappearance. It was mentioned that a globe of fire had fallen at the foot of the mountain of Tigayga, which bounds the valley of Orotava to the west, and that it had made a deep hole in the earth:- - search was made respecting the truth of this assertion, but it did not lead E 2 
to any positive result. I was likewise informed that similar globes of fire were seen traversing the Llano de Gaspar, the spot which I have mentioned as bearing such evident marks of the effects of the water. My informant, who was a small farmer living near Tigayga, and almost on a level with the Llano de Gaspar, likewise added, "that all the heaths appeared to be on fire; and at the same time $I$ saw a column of water several fathoms wide move across the top of the valley."

I will now resume the thread of my narrative to the Peak: and for the purpose of pointing out the devastation committed in 1826, I shall incur the risk of being thought tedious, by enumerating the ravines which I crossed at the spot where the waterspout appeared to have burst. The first was Barranco de Ilano de Gaspar; it was of some depth, and exposed a stratum of basaltic lava, a species of puzzolana of considerable thickness, and a brown volcanic mud resting on a bed of close black lava. A little to the west were two new ravines, which united into one at a short distance from the commencement, and formed the barranco which did so much mischief to the port of Orotava. The next was a new ravine, and is only remarkable for being the spot where you take leave of the luxuriant vegetation of the third zone, and enter that of the cytisus, which may be termed the fourth zone of plants. The surface here is a brown volcanic mud mixed with small pieces of lava, forming a hard breccia or conglomerate, with a slight covering of vegetable mould, which in many places between the ravines was completely washed away by the spray of the water.

Towards the south-western extremity of the Llano de Gaspar is a spot named the Camina del Alta, where there is a stream of trachytic lava that has separated at a short distance above, and formed a sort of half-circle: the two streams are nearly destitute of vegetation. Another column of water appears to have burst here, and made three or four ravines, which converge into one a few hundred feet below. At 8.30 A.M. we entered a part of the inclined plane called Chasquitas Abaxo and Chasquitas Arriba. The ravines here are very numerous, and some are so close together that there is hardly space sufficient to pass between them. Within a few hundred yards I crossed eleven, which were all formed in 1826; and in the upper part of Chasquitas Arriba the surface was cut into almost innumerable trenches of various depths, according to the force of the water or the compactness of the lava.

When we gained the top of a rather steep acclivity called 
Lomo de la Calavera, we met with a new barranco running into an ancient one of the same name as the hill; and about three-quarters of a mile from it we came to Barranco Juradillo, which is of an immense breadth and depth. At the spot where we crossed it the torrent bad divided itself into two branches, forming a sort of islet in the centre. The sides of the ravine were composed of various strata of lava and mud: the superior stratum was basaltic trap, occasionally inclined to a columnar formation; the second was a brown volcanic mud, about ten feet thick, below which was trap in laminar masses, volcanic breccia, and a sort of colorific earth. A short distance beyond Juradillo we passed on our left hand a hill of pumice*, which had been cut down in a perpendicular manner to the depth of at least eighty feet by the waterspout of 1826 .

The surface now entirely consisted of white rapilli partly decomposed, and masses of porphyritic lava, occasionally mixed with veins of pumice in the centre. Some time before we gained this elevation we found vegetation gradually becoming less luxuriant and more and more scanty, till here it was reduced to one variety only, the mountain broom (Spartium nubigenum), which is the last plant of the upper regions; and indicates the fifth and highest zone of plants. The dry, close, and ligneous formation of its leaves fully enables it to support the immense difference of temperature which it is obliged to undergo every four-and-twenty hours. During the summer season, in the day-time, the intensity of the solar rays is almost insupportable on account of the nature of the soil and the clearness and rarefaction of the air: on the contrary, the night air is excessively cold and moist. In winter the snow is permanent for some months, which, joined to the great elevation, produces a cold equal to that of the arctic regions.

At 10 P.M. we passed a spot called the Ultimo Pino (last pine), and had a view of the foot of the Peak, which bore W. by N. of us. The view on our right was a novelty to a person who was not accustomed to ascend great elevations. The valleys below were filled with vapours, whilst the sea and the regions above were quite clear. Objects below were unusually refracted. Two brigantines, which were just in the horizon, presented inverted images of some of their parts; but what was very singular, they occasionally altered their form: sometimes

- At this spot the waterspout brought to light two earthen bowls which had belonged to the Guanches. The possessor of them, Don Lorenzo Machado, very kindly presented me with one of them; it is made of argillaceous earth, mixed with a black volcanic sand, and is sun-dried: it holds about 200 cubic inches of water: 
the masts and ship appeared as if they were separated, then the masts touched each other, and afterwards rapidly increased in length, presenting quite a distorted appearance. The sea looked as if it were on a level with the eye; and although it was four or five miles off, the ripple upon the water was distinctly visible. This refraction was probably caused by the difference of temperature between the lower and upper stratum of air (18 of Fahrenheit), which produced a medium of varied density; and from the extreme evaporation over the sea, the refractive power there was small, but gradually increased to the point of observation, which possibly was its utmost limit, as after we ascended a few yards this unusual refraction or mirage went off, and the vessels assumed their usual appearance.

[To be continued.]

VI. A direct Method of finding the shortest Distance between two Points on the Earth's Surface when their Geographical Position is given. By James Ivory, Esq. M.A. F.R.S. \&c.*

THE geometers who, supposing that the earth is an oblate elliptical spheroid of revolution, have investigated rules for computing the shortest distance between two points on its surface, usually assume that there are given the two latitudes and the angle which the geodetical line makes with the meridian of one of the points. The direct problem for deducing the geodetical distance from the geographical position of the two points has not hitherto been solved. In the Conn. des Tems for 1832, M. Puissant has given formulæ which supply this defect. But his method merely consists in deriving from the two latitudes and the difference of longitude, what is necessary for applying the formula for the shortest distance published long ago by $M$. Legendre. I shall here shortly explain a different solution of the problem, which I lately obtained; according to which the shortest distance of two points on the earth's surface is expressed by means of their latitudes and the inclination to the equator of the great circle of the celestial sphere that passes through them.

The radius of the equator of an oblate elliptical spheroid of revolution being represented by unit, and the semipolar axis by $\sqrt{1-e^{2}}$, let $\lambda$ denote the latitude of a point on the surface, and $\psi$ the longitude reckoned from a fixed meridian : then, if $x, y, z$ be the three coordinates of the point, the ori-

- Communicated by the Author. 